\title{
DESEMPENHO SILVICULTURAL DE CLONES DE EUCALIPTO E CARACTERÍSTICAS AGRONÔMICAS DE MILHO CULTIVADOS EM SISTEMA SILVIAGRÍCOLA ${ }^{1}$
}

Renato Luiz Grisi Macedo ${ }^{2}$, Rozimeiry Gomes Bezerra ${ }^{3}$, Nelson Venturin ${ }^{2}$, Rodrigo Silva do Vale ${ }^{4}$ e Tadário

Kamel de Oliveira ${ }^{5}$

\begin{abstract}
RESUMO - Com o objetivo de avaliar as respostas do eucalipto e do milho cultivados em sistemas silviagrícolas, implantou-se um experimento em Paracatu, MG, constituído por quatro clones de eucalipto (dois clones de Eucalyptus camaldulensis, códigos 137 e 180; dois clones de Eucalyptus urophylla, códigos 13 e 44), dispostos no espaçamento de $10 \mathrm{~m} \mathrm{x} 4 \mathrm{~m}$, consorciados nas entre linhas com a cultura do milho. Utilizou-se o delineamento experimental em blocos casualizados (DBC), com quatro tratamentos (quatro clones de eucalipto) e seis blocos. Para a cultura do milho (cultivar BR 205), empregou-se o delineamento experimental em blocos casualizados (seis blocos), no esquema de parcelas subdivididas ( 4 × 2 mais um monocultivo, num total de nove tratamentos). As parcelas foram constituídas pelos sistemas consorciados de milho com quatro clones de eucalipto e pela cultura solteira de milho. As subparcelas foram constituídas por duas distâncias das linhas de plantio de milho em relação às linhas de plantio dos clones de eucalipto: primeira e segunda linhas de plantio do milho, adjacentes à linha do eucalipto (1,8 e 2,7 m) e quarta e quinta linhas de plantio de milho, central à linha do eucalipto (4,5 e 5,4 m). Os clones de E. camaldulensis apresentaram sobrevivência, altura, volume/árvore e volume/ ha superiores aos de E. urophylla. As maiores médias de diâmetro à altura do peito, volume/árvore e volume/ ha e forma retilínea do fuste foram observadas no clone de E. camaldulensis 137 , assim como o menor rendimento do milho. A produção de milho nos sistemas consorciados com clones de eucalipto foi menor que a obtida em monocultivo. O maior rendimento de grãos de milho nos sistemas consorciados com clones de eucalipto foi obtido nas linhas centrais de plantio.
\end{abstract}

Palavras-chave: Sistemas Agroflorestais, clones de eucalipto e milho.

\section{SILVICULTURAL PERFORMANCE OF EUCALYPTUS CLONES AND AGRONOMIC CHARACTERISTIC OF CORN PLANTED IN AGROFORESTRY SYSTEMS}

\begin{abstract}
An experiment based on Agroforestry System was conducted in Paracatu, MG. It consisted of four eucalyptus clones (two E. camaldulensis clones, codes 137 and 180, and two E. urophylla clones, codes 13 and 44) planted at 10m $x 4 m$ spacing intercropped with corn (cultivar BR 205) between rows. The experiment was arranged in a randomized block design with four treatments (4 eucalyptus clones) distributed in six blocks. The randomized block ( 6 blocks) design with split-plots ( $4 \times 2$, plus 1 monoculture, in a total of 9 treatments) was used for the corn culture. Plots consisted of systems of corn intercropped with four eucalypts clones and single-crop corn cultivation. The split-plots consisted of two corn rows set apart from the eucalyptus rows:
\end{abstract}

\footnotetext{
${ }^{1}$ Recebido em 27.03.2003 e aceito para publicação em 05.04.2006.

${ }^{2}$ Departamento de Ciências Florestais da Universidade Federal de Lavras (UFLA), 37200-000 Lavras-MG. E-mail:<rlgrisi@ ufla.br>.

${ }^{3}$ Departamento de Engenharia Florestal da Universidade Federal do Mato Grosso. 78060-900 Cuiabá-MT.

${ }^{4}$ Instituto de Ciências Agrárias da Universidade Federal Rural da Amazônia-IAC/UFRA. Belém-PA. E-mail:<rodrigo.vale@ ufra.edu.br>.

${ }^{5}$ Embrapa Acre. Rodovia BR-364, km 14, CP 321, 69908-970 Rio Branco-AC. E-mail: <tadario@ufla.br>.
} 


\begin{abstract}
the first and second corn rows adjacent to the eucalyptus rows $(1.8$ and $2.7 \mathrm{~m})$ and the fourth and fifth corn rows in the center of the eucaliptus rows $(4.5$ and $5.4 \mathrm{~m})$. E. camaldulensis clones had survival, height, volumel tree and volume/ha higher than $\boldsymbol{E}$. urophylla clones. Higher means of diameter at breast height, volume/ tree, volume/ha and tree stem form were found for $\boldsymbol{E}$. camaldulensis 137 clones, as well as lower corn yield. Corn production in intercropped systems with eucalyptus clones was lower than in monoculture. The highest corn yield in the Agroforestry System with eucalyptus was obtained in the central planting rows.
\end{abstract}

Keywords: Agroforestry Systems, eucalyptus clones and corn.

\section{INTRODUÇÃO}

A região de cerrado é apta para reflorestamentos, apesar de apresentar elevado déficit hídrico. Um fator limitante para o crescimento das plantas, nessa região, é a severidade da estação seca, que normalmente se estende de abril a setembro, exigindo espécies perenes bem adaptadas. Mesmo durante os meses de maior intensidade pluviométrica (dezembro a janeiro), é comum o surgimento de veranicos caracterizados por períodos longos sem chuva, associados a uma alta radiação solar e alto potencial de evapotranspiração (WOLF, 1975, citado por LOPES, 1983). Dentre as espécies mais estudadas para essas condições ambientais, destacamse o Eucalyptus camaldulensis e o Eucalyptus urophylla.

A potencialidade do Eucalyptus urophylla e Eucalyptus camaldulensis tem sido descrita por vários autores, em diferentes países e em diversas condições de ambiente em regiões tropicais (GOLFARI, 1975). Tal plasticidade se deve diretamente à amplitude de ocorrência natural e à diversidade ecotípica encontrada no "habitat" dessas espécies.

Na região do cerrado brasileiro, também é destaque a produção agrícola de culturas anuais como o milho. Embora o Brasil seja um dos maiores produtores mundiais desse grão, a produtividade nacional, ao redor de 2300 $\mathrm{kg} / \mathrm{ha}$, é ainda considerada muito baixa (BULL e CANTARELLA, 1983). O Estado de Minas Gerais vem se destacando nos últimos anos como o nono maior produtor de milho do Brasil, com uma produtividade média de aproximadamente $2575 \mathrm{~kg} / \mathrm{ha}$ (ANUÁRIO, 1995).

O milho é particularmente interessante para a formação de sistemas consorciados com florestas devido à sua simplicidade de condução e ao seu melhor comportamento diante de diversidades climáticas. Schreiner e Baggio (1984) consideraram que um dos principais fatores para que um cultivo consorciado seja eficiente é a complementação entre os cultivares envolvidos, já que, pelo menos durante parte de seu ciclo, há uma forte interação entre eles.

Compatibilizando a produção florestal com a produção agropecuária, os sistemas agroflorestais despertam interesse, em razão, principalmente, dos altos custos envolvidos na implantação e manutenção de florestas e da crescente pressão quanto à necessidade de conduzir empreendimentos de modo mais harmônico com o ambiente. Nos sistemas agroflorestais, espécies lenhosas são utilizadas em associações deliberadas com cultivos agrícolas e, ou, animais na mesma área, de forma simultânea ou seqüencial, otimizando a terra e a rentabilidade do empreendimento (BEZERRA, 1997; MACEDO et al., 2001).

Assis (1996) observou que no espaçamento de $9 \mathrm{~m}$ x $1 \mathrm{~m}$ ocorreu grande quantidade de ervas daninhas competindo com o eucalipto por água e nutrientes, devido à grande área exposta nas entrelinhas de plantio. Essa constatação evidencia a importância de haver culturas agrícolas ou forrageiras nas entrelinhas de plantios florestais, principalmente quando o espaçamento é amplo.

De acordo com Moniz (1987), a cultura do milho em associação inicial com o eucalipto pode ser uma prática interessante, uma vez que não afeta a sobrevivência da espécie florestal. Além disso, esse autor constatou que o consórcio de eucalipto ( $3 \mathrm{~m}$ $\mathrm{x} 2 \mathrm{~m}$ ) com uma fileira de milho proporcionou maior produção de grãos por planta, chegando a superar o monocultivo do milho, e proporcionou a diminuição dos custos de implantação florestal entre 59,75 e 79,43\%, dependendo de sua densidade. Essa viabilidade econômica foi observada também por Castillo (1977), que constatou que o consórcio milho x eucalipto diminuiu os custos do reflorestamento em torno de $60 \%$. 
O milho e o eucalipto, em virtude de suas potencialidades econômicas e da magnitude das áreas plantadas anualmente, constituem, portanto, duas culturas importantes para o país. Portanto, o cultivo simultâneo dessas duas espécies na mesma área deverá ser encarado como uma hipótese de estudo, sobretudo, em regiões de grande potencial agroflorestal, como é o caso do cerrado.

O objetivo deste trabalho foi avaliar o desempenho silvicultural de quatro clones de eucalipto e características agronômicas da cultura do milho cultivados em sistema silviagrícola.

\section{MATERIAL E MÉTODOS}

O experimento foi instalado na região noroeste do Estado de Minas Gerais, no Município de Paracatu, a $17^{\circ} 36^{\prime}$ de latitude sul e $46^{\circ} 42^{\prime}$ de longitude oeste, com altitude de $550 \mathrm{~m}$.

O clima da região é tropical úmido de savana, com inverno seco e verão chuvoso, do tipo Aw, conforme a classificação de Köppen. A temperatura média anual é de $22,6^{\circ} \mathrm{C}$, tendo uma média mensal de $18^{\circ} \mathrm{C}$ na estação mais fria e $29,1^{\circ} \mathrm{C}$ na mais quente. A precipitação média anual é de $1.450 \mathrm{~mm}$, apresentando, nos meses mais secos, precipitações médias mensais inferiores a 60 mm (BRASIL, 1992).

O solo predominante na área experimental é do tipo Latossolo Vermelho-Amarelo distrófico. Essa área foi preparada em dezembro de 1994, para ser utilizada em sistemas consorciados com clones de eucalipto plantados no espaçamento de $10 \mathrm{~m} \mathrm{x} 4 \mathrm{~m}$, sendo que no primeiro ano (1994) as suas entrelinhas foram consorciadas com a cultura do arroz e, no segundo (1995), com a cultura da soja, conforme as recomendações técnicas propostas por Macedo e Oliveira (1996). As parcelas experimentais foram formadas por seis linhas de 12 árvores (72 árvores), em espaçamento de $10 \mathrm{~m}$ nas entrelinhas e $4 \mathrm{~m}$ entre árvores. As árvores externas foram consideradas como bordadura, sendo a área útil de cada parcela constituída por árvores de eucalipto dispostas em quatro linhas de 10 plantas cada. As linhas de plantio foram orientadas no sentido leste-oeste, para permitir maior insolação às culturas consorciadas nas entrelinhas.

Em agosto de 1996, nas entrelinhas da cultura do eucalipto fizeram-se uma aração leve e duas gradagens niveladoras. Utilizou-se calcário zincal MMA 85\% de PRNT, à razão de 1,0 t/ha.
Quando o eucalipto estava com 24 meses (dezembro de 1996) foi instalado o experimento de consorciação com o milho. Nas mesmas entrelinhas do eucalipto, plantou-se a cultura do milho (Zea mays L.), utilizando o cultivar BR 205 de ciclo tardio. Plantaram-se oito linhas de milho espaçadas em $0,90 \mathrm{~m}$, com a densidade média de cinco sementes por metro linear, a uma distância aproximada de 1,8 $\mathrm{m}$ das linhas de eucalipto.

Para a adubação de plantio do milho, utilizaramse $300 \mathrm{~kg} / \mathrm{ha}$ da fórmula NPK $05-25-15+\mathrm{Zn}^{+}$, enquanto para a adubação em cobertura foram aplicados $90 \mathrm{~kg} /$ ha de uréia agrícola, aproximadamente 40 dias após a germinação (contendo as plantas de milho em torno de três pares de folhas).

Para avaliar o desempenho e a produção da cultura do milho plantado no sistema consorciado com clones de eucalipto, utilizou-se o delineamento experimental em blocos casualizados (DBC) com seis blocos, sendo os tratamentos dispostos num esquema de parcelas subdivididas ( 4 × 2 mais um monocultivo, totalizando nove tratamentos). As parcelas foram constituídas pelos consórcios de milho com os quatro clones de eucalipto e duas subparcelas. As subparcelas foram constituídas das avaliações das primeiras linhas de milho adjacentes à linha do eucalipto e das duas linhas centrais, ou seja, a primeira e segunda linhas $(1,8$ e $2,7 \mathrm{~m})$ de plantio de milho e a outra composta pela quarta e quinta linhas (4,5 e 5,4 m). Aárea útil de cada subparcela foi constituída por duas linhas de $5 \mathrm{~m}$ lineares.

Aos 28 meses de idade, avaliaram-se sobrevivência, a altura total, o diâmetro à altura do peito (DAP), a área de projeção de copa e a forma do fuste dos clones de eucalipto. O volume por árvore foi estimado com o fator de forma 0,43 e o volume de madeira por hectare, calculado com ajuste de acordo com a sobrevivência em cada tratamento. Foram o estande final (número de plantas de milho que chegaram à fase de colheita), e a altura de plantas (média de 10 plantas de milho, na área útil de cada subparcela, medida da superfície do solo até a inserção do pendão). Realizou-se a colheita manual das espigas, sendo avaliados o peso de espiga de milho, sem palha, e o rendimento de grãos.

Após a determinação da umidade, calculou-se o rendimento de grãos de cada subparcela, corrigida para umidade de $14 \%$ na base úmida, sendo posteriormente convertida para quilogramas por hectare $(\mathrm{kg} / \mathrm{ha})$.

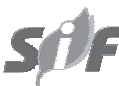

R. Árvore, Viçosa-MG, v.30, n.5, p.701-709, 2006 
Todos os valores das características avaliadas foram submetidos à análise de variância. Quando os efeitos dos tratamentos (clones, distâncias e interação) se mostraram significativos, foram realizadas comparações de médias, por meio do teste de Tukey a 5\% de probabilidade. Para análise de variância da característica porcentagem de sobrevivência do eucalipto, os dados foram transformados em arc sen $\sqrt{x / 100}$, sendo $x$ a porcentagem de sobrevivência.

\section{RESULTADOS E DISCUSSÃO}

Observou-se diferença significativa na sobrevivência, altura, DAP, volume ( $\mathrm{m}^{3}$ /árvore e $\mathrm{m}^{3}$ / ha), área de projeção da copa e forma retilínea do fuste entre os clones de eucaliptos testados (Quadro 1).

Constatou-se alta porcentagem de sobrevivência no campo, o que denota que os clones de eucalipto apresentaram excelente capacidade adaptativa e de estabelecimento nas condições edafoclimáticas do sítio em questão. A porcentagem de sobrevivência apresentada pelos clones de E. camaldulensis foi superior às observadas nos clones de E. urophylla.

De modo geral, os clones de E. camaldulensis (180 e 137) apresentaram-se com alturas médias superiores às obtidas nos clones de E. urophylla (44 e 13) (Quadro 1).

Macedo et al. (2000) realçaram que a capacidade potencial de estabelecimento das espécies de rápido crescimento normalmente pode ser observada no campo, nos primeiros períodos pós-plantio, avaliada através da sua porcentagem de sobrevivência. Sob as condições de campo, normalmente as mudas de diferentes espécies florestais se diferem em suas expressões fenotípicas de adaptação e de vigor.

As diferenças observadas entre as alturas médias dos clones evidenciam que estes apresentam diferentes capacidades genéticas de exploração do potencial produtivo do "habitat" de introdução, estando provavelmente relacionados às suas plasticidades fenotípicas. Os valores médios de altura observados nos clones de eucalipto provavelmente estão relacionados ao amplo espaçamento de plantio $(10 \times 4 \mathrm{~m})$ e à menor competição por água no solo.

O crescimento em altura é um dos parâmetros mais importantes para determinar o estabelecimento das árvores em competição, sendo um dos índices mais seguros para comprovar se a espécie foi ou não plantada em local apropriado (GOLFARI, 1975).

Em relação às médias do diâmetro À altura do peito (DAP), o clone de Eucalyptus camaldulensis 137 apresentou o maior valor (Quadro 1).

De modo geral, os valores médios de DAP observados nos clones de eucalipto deste trabalho foram superiores aos encontrados por Moura e Costa (1985); Albino e Tomazello Filho (1985) e Ferreira et al. (1987), nas mesmas espécies em região de Cerrado, porém plantados em espaçamentos mais densos de $3 \times 2 \mathrm{~m}$.

Essa superioridade no crescimento diamétrico foi devida, provavelmente, à utilização de espaçamentos de plantios mais amplos (10 x 4 m). Couto (1977), estudando cinco espaçamentos diferentes de $E$. urophylla até 93 meses de idade, verificou que a altura e o diâmetro médio das plantas aumentaram com o espaçamento. Vários autores (PATIÑO-VALERA, 1986; GOMES, 1994; BERNARDO, 1995) consideraram que, na maioria das espécies florestais de rápido crescimento, as respostas crescentes em crescimento diamétrico geralmente estão relacionadas com o aumento nos espaçamentos de plantio.

Quadro 1 - Valores médios da porcentagem de sobrevivência, altura, DAP, volume/árvore, volume/ha, área de projeção de copa e forma retilínea do fuste, avaliados aos 28 meses de idade, nos clones de E. camaldulensis (137 e $180)$ e E. urophylla (13 e 44), cultivados em sistema silviagrícola

Table 1 - Mean values of survival rate, height, DBH, value/tree, volume/ha, area of crown projection and stem form assessed at 28 months of age, for E. camaldulensis (137 and 180) and E. urophylla (13 and 44) clones

\begin{tabular}{|c|c|c|c|c|c|c|c|}
\hline Tratamentos & $\begin{array}{c}\text { Sobrevivência } \\
(\%)\end{array}$ & $\begin{array}{l}\text { Altura } \\
(\mathrm{m})\end{array}$ & $\begin{array}{l}\text { DAP } \\
(\mathrm{cm})\end{array}$ & $\begin{array}{c}\text { Volume } \\
\text { (m³/árvore) }\end{array}$ & $\begin{array}{l}\text { Volume } \\
\left(\mathrm{m}^{3} / \mathrm{ha}\right)\end{array}$ & $\begin{array}{l}\text { Área Proj. } \\
\text { Copa }\left(\mathrm{m}^{2}\right)\end{array}$ & $\begin{array}{c}\text { Forma Ret. } \\
\text { fuste }(\%)\end{array}$ \\
\hline Clone 137 & $100,00 \mathrm{a}$ & $13,92 \mathrm{a}$ & 15,222 a & $0,1097 \mathrm{a}$ & 27,4413 a & $20,88 \mathrm{c}$ & 99,72 a \\
\hline Clone 180 & $100,00 \mathrm{a}$ & $14,25 \mathrm{a}$ & $14,480 \mathrm{~b}$ & $0,1020 \mathrm{~b}$ & $25,5042 b$ & $26,04 \mathrm{ab}$ & $98,88 \mathrm{ab}$ \\
\hline Clone 44 & $97,96 \mathrm{~b}$ & $11,82 \mathrm{~b}$ & $14,193 \mathrm{~b}$ & $0,0797 \mathrm{c}$ & $19,9394 \mathrm{c}$ & $24,73 \mathrm{~b}$ & $80,74 \mathrm{c}$ \\
\hline Clone 13 & $98,64 \mathrm{~b}$ & $11,07 \mathrm{c}$ & $14,285 \mathrm{~b}$ & $0,0782 \mathrm{c}$ & $19,5649 \mathrm{c}$ & 29,34 a & $91,71 \mathrm{bc}$ \\
\hline
\end{tabular}

Médias seguidas por mesma letra nas colunas não diferem entre si, pelo teste de Tukey a $5 \%$ de probabilidade.

R. Árvore, Viçosa-MG, v.30, n.5, p.701-709, 2006 
Os valores médios de volume por árvore e por hectare dos clones de eucalipto, avaliados aos 28 meses de idade, apresentaram a seguinte ordem decrescente de produção: E. camaldulensis (137 e 180) e E. urophylla (44 e 13) (Quadro 1).

Os valores médios de volume por árvore, obtidos de todos os clones, foram semelhantes ou superiores aos conseguidos por Moura e Costa (1985), nas mesmas espécies de Eucalyptus em condições edafoclimáticas semelhantes, porém plantadas no espaçamento de 3 x $2 \mathrm{~m}$. No entanto, comparando os valores médios obtidos de volume por hectare $\left(\mathrm{m}^{3} / \mathrm{ha}\right)$, percebeu-se que foram inferiores aos observados pelos autores citados, provavelmente em função do maior espaçamento utilizado no presente trabalho $(10 \times 4 \mathrm{~m})$.

Os valores médios de volume por árvore e por hectare na idade de avaliação de 28 meses possivelmente sejam reflexos diretos do reduzido número de árvores de eucalipto por hectare (250 árvores/hectare), o que indica ausência de competição interespecífica pelos fatores de produção disponíveis no local e demonstram que a capacidade-suporte da região de introdução foi suficiente para favorecer o estabelecimento satisfatório dos clones de eucalipto, que se adaptaram bem às condições ecológicas da região.

Quanto à área de projeção da copa, o clone 137 apresentou a menor área expansiva de copa lateral (Quadro 1). Essa característica é almejada em consórcios agroflorestais, principalmente por possibilitar maior entrada de luz nos estratos inferiores consorciados nas entrelinhas, sendo esta uma das formas de expressão do potencial genético dos clones de eucalipto a serem inseridos em sistemas silviagrícolas.

Em relação ao número de árvores com forma retilínea de fuste, os clones 137 e 180 se destacaram com os maiores valores e o clone 44, com o menor valor (Quadro 1). Segundo Bernardo (1995) a forma do fuste é uma característica extremamente variável entre espécies e mesmo dentro de algumas espécies, em função das suas procedências, porém essencial para se determinar a qualidade da madeira.

Os resultados referentes às análises de variância das características agronômicas do milho indicaram efeito significativo dos clones para estande final. Houve efeito significativo das distâncias das linhas de plantio de milho em relação às de eucalipto e da interação entre distância e tratamento (consórcio do milho com clones de eucalipto e monocultivo), quanto às características altura de plantas, peso de espigas e rendimento de grãos.

Observam-se, no Quadro 2, as médias dos tratamentos (consórcios e monocultivo) para estande final, havendo uma influência acentuada dos clones de eucalipto no número de plantas por subparcela. O maior valor do estande final de milho foi obtido em monocultivo, e valores decrescentes foram obtidos, respectivamente, nos sistemas consorciados com os clones de eucalipto 180, 13, 44 e 137.

Observou-se que as diferentes distâncias de afastamento em relação às linhas de eucalipto não apresentaram diferenças significativas quanto ao número de plantas por subparcela. Não houve efeito da interação clones e distâncias.

De modo geral, a altura das plantas de milho consorciadas com os clones de eucalipto 180 e 44 foram semelhantes às do monocultivo, porém apresentaram valores superiores aos verificados nos consórcios com os clones 13 e 137, independentemente das distâncias de plantio (Quadro 3).

A altura média das plantas de milho consorciadas com clones de eucalipto situadas a 4,5-5,4 m de distância das linhas de eucalipto foi superior às alturas daquelas localizadas a 1,8-2,7 m, exceto no clone 137 , possivelmente devido maior luminosidade incidente no meio das ruas de plantio dos clones de eucalipto, orientadas na direção leste-oeste (Quadro 3).

Quadro 2 - Valores médios de estande final da cultura de milho (Zea mays L.) consorciada com clones de eucalipto e em monocultivo

Table 2 - Mean values of final corn stand (Zea mays L.) intercropped with eucalyptus clones and in monoculture

\begin{tabular}{lcccc}
\hline Tratamentos & Milho + & Milho + & Milho + & Milho + \\
\hline & Clone 137 & Clone 44 & Clone 13 & Clone 180 \\
$\begin{array}{l}\text { Estande final } \\
\left(\mathrm{n}^{\circ} \text { plantas/subparcela) }\right.\end{array}$ & $25,70 \mathrm{c}$ & $29,75 \mathrm{bc}$ & $31,95 \mathrm{~b}$ & $34,08 \mathrm{~b}$ \\
\hline
\end{tabular}

Médias seguidas da mesma letra na linha não diferem entre si, pelo teste de Tukey a 5\% de probabilidade. 
Quadro 3 - Valores médios de altura de plantas, peso de espigas e rendimento de grãos da cultura de milho (Zea mays L.) em função do consórcio com diferentes clones de eucalipto, do monocultivo e das distâncias das linhas de plantio em relação ao eucalipto

Table 3 - Mean values for plant height, corn ear weight and corn yield (Zea mays L.) as a function of intercropping with different eucalyptus clones, monoculture and the distance of rows from eucalyptus

\begin{tabular}{|c|c|c|c|c|c|c|}
\hline \multirow[t]{2}{*}{ Tratamentos } & \multicolumn{2}{|c|}{ Altura de Planta $(\mathrm{cm})$} & \multicolumn{2}{|c|}{ Peso de Espiga (gramas/subparcela) } & \multicolumn{2}{|c|}{ Rendimento de Grãos (kg/ha } \\
\hline & $1,8-2,7 \mathrm{~m}$ & $4,5-5,4 \mathrm{~m}$ & $1,8-2,7 \mathrm{~m}$ & $4,5-5,4 \mathrm{~m}$ & $1,8-2,7 \mathrm{~m}$ & $4,5-5,4 \mathrm{~m}$ \\
\hline Milho + C & $159,40 \mathrm{Ac}$ & & & $1329,16 \mathrm{Ac}$ & & $3,61 \mathrm{Ac}$ \\
\hline 44 & Babc & & & & $3 b c$ & $\mathrm{Ab}$ \\
\hline e 13 & 162,5 & $\mathrm{Aab}$ & $5 \mathrm{Bc}$ & $\mathrm{Ab}$ & $3 \mathrm{Bc}$ & $1922,35 \mathrm{Ab}$ \\
\hline lone 180 & $177,97 \mathrm{Bab}$ & & $1816,25 \mathrm{Bb}$ & $2386,66 \mathrm{Ab}$ & $1440,83 \mathrm{Bb}$ & $2072,74 \mathrm{Ab}$ \\
\hline Monocultivo & $180,33 \quad \mathrm{a}$ & $180,33 \mathrm{ab}$ & $4832,50 \quad \mathrm{a}$ & $4832,50 \quad \mathrm{a}$ & $4268,73 \quad a$ & $4268,73 \quad \mathrm{a}$ \\
\hline
\end{tabular}

Médias seguidas da mesma letra minúscula nas colunas não diferem entre si quanto aos consórcios de milho com clones de eucalipto e em monocultivo. Médias seguidas da mesma letra maiúscula nas linhas não diferem entre si quanto à distância das linhas de plantio de milho em relação às de eucalipto, pelo teste de Tukey, a 5\% de probabilidade.

Quanto ao peso das espigas, o obtido em monocultivo foi superior àquele observado nos consórcios, nas duas distâncias (Quadro 3). Provavelmente, isso é resultado de maior competição por luz nos consórcios, uma vez que suas espigas tiveram diminuição significativa em tamanho, além da mal formação de grãos, ocorrendo muitas espigas sem grão ou com número reduzido. Aliado a esse fato, verificouse menor estande nos sistemas consorciados (Quadro 2). O decréscimo na radiação solar disponível às plantas, além de afetar o desenvolvimento das espigas, provoca diminuição no número de espigas com grãos por planta e no peso de 100 grãos (FLESCH, 1978; COSTA, 1994).

De modo geral, o peso médio das espigas de plantas de milho consorciadas com clones de eucalipto das linhas de plantio situadas a 4,5-5,4 $\mathrm{m}$ de distância das linhas dos clones de eucalipto foi superior aos pesos de espigas das linhas de 1,8-2,7 m (Quadro 3). É provável que a maior disponibilidade de luz existente no meio das entrelinhas, decorrente das maiores distâncias de afastamento das linhas de plantio do eucalipto, tenha sido o fator determinante para a obtenção de espigas mais pesadas.

Nos consórcios de milho com os clones de eucalipto 137 e 13, obtiveram-se os menores pesos de espigas (Quadro 3), a 1,8-2,7 m. Na distância de 4,5 - 5,4 m, o menor peso de espigas foi verificado no consórcio de milho com o clone 137 .

O rendimento médio de grãos de milho obtido em monocultivo (»4.269 kg/ha) foi superior à média nacional (2.300 kg/ha), segundo Büll e Cantarella (1993), e à do Estado de Minas Gerais (2.575 kg/ha), segundo
Anuário (1995), porém inferior à produção média esperada para o cultivar BR 205. Os rendimentos de grãos obtidos nos sistemas consorciados apresentaram, em sua maioria, valores abaixo desses.

Comparando a produção média de grãos de milho do monocultivo com a produção dos sistemas consorciados com clones de eucalipto, observou-se redução na produção média nesses sistemas consorciados de $81,04,69,69,58,85$; e 58,62\%, respectivamente nos consórcios com os clones 137 , 13,180 e 44 . A mesma tendência foi observada por Bezerra (1997), quando compararou a produção média de soja do monocultivo com a produção dos mesmos sistemas consorciados com os mesmos clones de eucalipto; porém, avaliados aos 17 meses de idade, observaram redução na produção média de 41,18, 20,82, 17,48; e 0,04\%, respectivamente, nos mesmos consórcios com os clones $137,13,180$ e 44.

Os baixos valores obtidos, na produção de grão de milho com os sistemas de monocultivo e consorciado provavelmente podem ser atribuídos à ocorrência de déficit hídrico durante os períodos de florescimento e formação da espiga. Vários autores (FANCELLI e DOURADO NETO, 1996; VOLPE, 1986; BÜLLe CANTARELLA, 1993; COSTA, 1994) associam a ocorrência de déficit hídrico nos respectivos períodos considerados anteriormente a problemas na cultura do milho relacionados com produção de espigas de menor tamanho, ausência de uma segunda espiga de milho por planta e de mal formação de grãos por espiga, com conseqüente redução no rendimento da cultura. 
A produção de grãos de milho obtida em monocultivo foi superior à observada nos sistemas consorciados, nas duas distâncias. Ao avaliar a produção somente entre os sistemas consorciados com os clones de eucalipto, observou-se que os consórcios de milho com os clones 44 e 180 foram os que obtiveram os melhores rendimentos, seguidos pelos consórcios de milho com os clones 13 e 137 , nas linhas a $1,8-2,7$ $m$ de distância do eucalipto. Na distância de 4,5 - 5,4 $\mathrm{m}$, o menor rendimento foi notado no consórcio entre o milho e o clone 137 (Quadro 3).

A menor produção de grãos de milho, observada no sistema consorciado com o clone de eucalipto 137 , provavelmente pode ser atribuída à maior competição exercida pelas árvores de eucalipto desse clone, que apresentou o maior vigor vegetativo e maior produção de biomassa, em comparação com os demais clones de eucalipto estudados (Quadro 1). O clone 137 destacouse quanto às características de maior DAP, altura, volume e forma retilínea do fuste, porém as produções de grãos de milho obtidos nos consórcios com esse clone foram inferiores às observadas nos demais clones. Provavelmente, esse clone exerceu maior pressão competitiva pelos fatores de produção (principalmente por nutrientes e água) exigidos e, ou, necessários para viabilizar seu estabelecimento e manter seu crescimento na região.

De modo geral, nos sistemas consorciados a produção média de grãos de milho colhido nas linhas de plantio entre 4,5 e 5,4 m de distância das linhas de plantio das árvores foi superior à produção obtida na distância de 1,8 a 2,7 m (Quadro 3). A produção média de grãos de milho, obtida na linha de plantio distanciada entre 1,8 e 2,7 $\mathrm{m}$ das linhas de plantio de eucalipto, apresentou uma redução de $29,68 \%$ em relação à produção média de grãos de milho obtida nas linhas de plantio mais distantes das árvores de eucalipto (entre 4,5 e 5,4 m de distância). Esses resultados provavelmente podem ser atribuídos ao maior tempo de sombreamento conferido às plantas de milho localizadas mais próximas das linhas de plantio de eucalipto.

A produção média de grãos de milho consorciado com clones de eucalipto 44, 13 e 180 apresentou valores superiores para o distanciamento de 4,5-5,4 $\mathrm{m}$ das linhas de eucalipto em relação à distância de 1,8-2,7 m, enquanto, as produções de grãos de milho consorciado com clones de eucalipto 137 , distanciados, respectivamente, 1,8
$-2,7$ e 4,5 - 5,4 $\mathrm{m}$ das linhas de eucalipto, apresentaram valores semelhantes entre si (Quadro 3).

As linhas de plantio de milho compreendidas entre as distâncias de 1,8 a 2,7 m dos sistemas consorciados com clones de eucalipto apresentaram reduções na produção de grãos de milho de $65,39,52,28,32,06$ e $30,49 \%$, respectivamente, nos consórcios com os clones 13, 44, 137 e 180, em relação às suas produções obtidas nas distâncias compreendidas entre 4,5 e 5,4 m das linhas de eucalipto.

De modo geral, os baixos valores médios de rendimento de grãos de milho obtidos nos sistemas consorciados com clones de eucalipto refletem limitações na disponibilidade e, ou, na utilização eficiente dos fatores de produção pela cultura do milho.

Em relação aos fatores de produção limitantes da cultura do milho, Chang (1981)e Jong et al. (1982) verificaram que a duração do período luminoso e a quantidade de radiação solar que chega à superfície das folhas, constituem um fator ambiental que pode limitar o rendimento dos cultivares de milho. Cal e Obendorf (1972) confirmaram que a temperatura e a radiação solar afetam a fotossíntese, a respiração e a translocação, bem como o desenvolvimento da cultura do milho. E ainda, Backer e Musgrave (1964) constataram que a curva de fotossíntese do milho guarda estreita relação com a radiação incidente, com uma estimativa do coeficiente de correlação de 0,98. Searbrook e Doos (1973) observaram que a produção decresce marcadamente em condições de redução de energia solar e é incrementada em condições de enriquecimento da luz.

\section{CONCLUSÕES}

O desenvolvimento dos clones de eucalipto consorciados com milho, após o consórcio com arroz e soja, é considerado satisfatório, em termos de sobrevivência, altura de plantas, diâmetro à altura do peito, volume/árvore, volume/ha e forma retilínea do fuste.

Os clones de E. camaldulensis apresentam sobrevivência, altura, volume/árvore e volume/ha superiores aos de E. urophylla.

O clone de E camaldulensis 137 apresenta maior diâmetro à altura do peito, volume/árvore e volume/ ha, forma retilínea do fuste e o menor rendimento de grãos de milho.

R. Árvore, Viçosa-MG, v.30, n.5, p.701-709, 2006 
O rendimento de grãos de milho nos sistemas consorciados com clones de eucalipto é menor que o obtido em monocultivo.

O maior rendimento de grãos de milho nos sistemas consorciados com clones de eucalipto é obtido nas linhas centrais de plantio.

\section{REFERÊNCIAS BIBLIOGRÁFICAS}

ALBINO, J.C.; TOMAZELLO FILHO, M.

Evolução de doze espécies/ procedências de Eucalyptus em três regiões bioclimáticas do estado de Minas Gerais. Planaltina-DF: Ministério da Agricultura, EMBRAPA-CPAC, 1985. 46p. (Boletim de Pesquisa, 25).

ANUÁRIO Estatístico do Brasil. Rio de Janeiro: IBGE, 1995. v. 55. p. 39.

ASSIS, R.L. Armazenamento de água no solo, produção de biomassa e avaliação do estado nutricional em plantios de Eucalyptus urophylla sob diferentes espaçamentos na região de Bocaiúva - MG. 1996. 72 f. Dissertação (Mestrado em Solos e Nutrição de Plantas) Universidade Federal de Lavras, Lavras, 1996.

BACHER, D.N.; MUSGRAVE, R.B. Photosynthesis under field conditions. V. Funder plant chamber studies of the effects on light on corn (Zea mays L.). Crop Science, n. 4, p. 127-31, 1964.

BERNARDO, A.L. Crescimento e eficiência nutricional de Eucalyptus spp sob diferentes espaçamentos na região de cerrado de Minas Gerais. 1995. $120 \mathrm{f}$. Dissertação (Mestrado em Ciências Florestais) Universidade Federal de Viçosa, Viçosa, MG, 1995.

BEZERRA, R.G. Consórcios de clones de eucalipto com soja e milho na região de cerrado no noroeste do Estado de Minas Gerais: um estudo de caso. 1997. $91 \mathrm{f}$. Dissertação (Mestrado em Ciências Florestais) Universidade Federal de Lavras, Lavras, 1997.

BRASIL. Ministério da Agricultura e Reforma Agrária. Departamento Nacional de Meteorologia. Normais climatológicas (1961-1990). Brasília: 1992.84 p.

R. Árvore, Viçosa-MG, v.30, n.5, p.701-709, 2006
BÜLl, L.T.; CANTARELLA, H. Cultura do milho: fatores que afetam a produtividade. Piracicaba: POTAFOS, 1993. 301p.

CAL, J.P.; OBENDORF, R.L. Differential growth of corn hubrids seeded at cold root zone temperatures. Crop Science, n. 12, p. 572-575, 1972.

CAStillo, C.A. Comportamento inicial de Eucalyptus deglupta Blume, associado com maiz (Sistema "taungya") en dos espaciamentos con y sin fertilización. 1977. 130 f. Dissertacion (Mestrado en Sistemas Agrofloretales) - UCR - CATIE, Turrialba, 1977.

CHANG, J.H. Corn yield in relation to photoperiod, nght temperature and solar radiation. Agricultural Metereology, n. 24, p. 253-262, 1981.

COSTA, A.F.S. da. Influencia das condições climáticas no crescimento e desenvolvimento de plantas de milho (Zea mays L.), avaliadoas em diferentes épocas de plantio. 1994. 109 f. Tese (Doutorado em Fitotecnia) - Universidade Federal de Viçosa, Viçosa, MG, 1994.

COUTO, L. Influencia do espaçamento no crescimento de Eucalyptus urophylla de origem híbrida, cultivada na região de Coronel Fabriciano. 1977. 54 f. Dissertação (Mestrado em Ciências Florestais). Universidade Federal de Viçosa, Viçosa, MG, 1977.

FANCELLI, A.L.; DOURADO NETO, D. Cultura do milho: aspectos fisiológicos e manejo da água. Piracicaba: POTAFOS, 1996. p. 1-4. (Informações Agronômicas, 73).

FERREIRA, J.E.M. et al. Teste de procedência de eucalipto para a região subúmida do Estado do Maranhão. Colombo: EMBRAPA-CNPF, 1987. p. 41-48. (Boletim de Pesquisa Florestal, 15).

FLESH, R.D. Efeitos de duas populações de plantas sobre o desenvolvimento das espigas em três híbridos simples de milho (Zea mays L.). 1978. $99 \mathrm{f}$. Dissertação (Mestrado em Agronomia) Universidade Federal do Rio Grande do Sul, Porto Alegre, 1978. 
GOLFARI, L. Zoneamento ecológico do Estado de Minas Gerais para reflorestamento. Belo Horizonte: $\mathrm{PND} / \mathrm{FAO} /$ IBDF-BRA/71/545, 1975. 65 p. (Série Técnica, 3).

GOMES, R.T. Efeito do espaçamento no crescimento e nas relações hídricas de Eucalyptus spp. na região de cerrado de Minas Gerais. 1994. 85 f. Dissertação (Mestrado em Ciências Florestais) - Universidade Federal de Viçosa, Viçosa, MG, 1994.

JONG, S.K.; BREWBAKER, J.L.; LEE, C.H. Effects of solar radiation on the performace of maize in 41 sucessive monthly plantings in Hawai. Crop Science, n. 22, p. 13-18. 1982.

LOPES, A.S. A calagem em solos sob cerrado. In: SIMPÓSIOSOBREACIDEZECALAGEMNOBRASIL, Campinas, 1983. Anais... Campinas: Sociedade Brasileira de Ciência do Solo, 1983. p. 214-245.

MACEDO, R.L.G.; OLIVEIRA, A.D. Sistemas agroflorestais: considerações técnicas e econômicas. Lavras: Universidade Federal de Lavras, 1996 (Projeto de Consultoria).

MACEDO, R.L.G. et al. Potencial de estabelecimento de clones de Hevea brasiliensis Muell Arg. (seringueira) introduzidos em sistemas agroflorestais com castanheira-do-brasil (Bertholletia excelsa Humb \& Bompl), em Lavras - MG. In: SIMPÓSIO INTERNACIONAL SOBRE ECOSSISTEMAS FLORESTAIS, 5., FOREST' 2000. 2000, Porto Seguro. Anais ... Rio de Janeiro: BIOSFERA, 2000. p. 159-161.

MACEDO, R.L.G.; VENTURIN, N.; TSUKAMOTO FILHO, A.A. Princípios de agrossilvicultura como subsídio do manejo sustentável. Informe Agropecuário, v. 29, n. 1/2, p. 15-26, 2001.
MONIZ, C.V.D. Comportamento inicial do eucalipto (Eucalyptus toreliana F. Muell) em plantio consorciado com milho (Zea mays L.) no Vale do Rio Doce, em Minas Gerais. 1987, 68 f. Dissertação (Mestrado em Ciências Florestais) - Universidade Federal de Viçosa, Viçosa, MG, 1987.

MOURA, V.P.G.; COSTA, S.M. C. Seleção de espécies e procedências de Eucalyptus, no eixo Campo Grande Três Lagoas MS, Região de Cerrados. Planaltina, DF: EMBRAPA-CPAC, 1985. 33 p. (Boletim de Pesquisa, 23).

PATIÑO-VALERA, F. Variação genética em progênies de Eucalyptus saligna Smith e sua interação com espaçamento. 1986. 192 f. Dissertação (Mestrado em Ciências Floretais) - Escola Superior de Agricultura Luiz de Queiroz, Piracicaba, 1986.

SCHEREINER, H.G.; BAGGIO, A.J. Culturas intercalares de milho (Zea mays L.) em reflorestamento de Pinus taeda L. no sul do Paraná. Colombo: EMBRAPA-CNPF, 1984. p. 26-49. (Boletim de Pesquisa Florestal, 8/9).

SEARBROOK, C.E.; DOSS, B.D. Leaf area index and radiation as related to corn yield.

Agronomy Journal, n. 51, p. 459-61. 1973.

VOLPE, C.A. Eficiência no uso da água, resistência estomática e parâmetros aerodinâmicos da cultura do milho (Zea mays L.) 1986. 204 f. Tese (Doutorado em Solos e Nutrição de Plantas) - Escola Superior de Agricultura Luiz de Queiroz, Piracicaba, 1986. 